\title{
Barriers and opportunities to successful local air quality management consultation in England
}

\author{
N. S. Leksmono ${ }^{1}$, F. Burnet ${ }^{1}$, P. Dorfman ${ }^{1}$, D. C. Gibbs ${ }^{2}$, \\ J. W. S. Longhurst ${ }^{1}$ \& E. L. C. Weitkamp ${ }^{1}$ \\ ${ }^{I}$ Faculty of Applied Sciences, University of the West of England, \\ Bristol, UK \\ ${ }^{2}$ Department of Geography, University of Hull, Hull, UK
}

\begin{abstract}
England now has some 10 years experience of the Local Air Quality Management (LAQM) process where local authorities are required to consult on their air quality findings with stakeholders and the public. The statutory basis for consultation is provided by the Environment Act 1995, part IV; the Act and subsequence Policy Guidance identify a range of statutory and non statutory consultees, including the public where it is appropriate that their views are taken into account in the local authority's decisions about LAQM. This paper will present the outcomes of a 2 year Economic and Social Research Council funded programme addressing how local authorities in England have discharged their air quality duties and responsibilities. Evidence from a questionnaire survey and case studies is presented. Data suggest that although local authorities genuinely attempt to engage with all stakeholders, current consultation processes are not working as well as they could. This suggests a re-think on the form and function of LAQM consultation processes is required. Barriers for and opportunities to effective consultation will be considered and the paper will conclude with a set of parameters that define an integrated LAQM consultation process.

Keywords: consultation, air quality management, England.
\end{abstract}




\section{Introduction}

\subsection{Legislative context}

The Environment Act 1995, part IV, requires local authorities to review and assess air quality in their area of jurisdiction and determine locations where concentrations of health-based air quality objectives are likely to be exceeded. The Act has also placed an obligation on local authorities to consult with local stakeholders as part of their local air quality management (LAQM) process. The Act [1] and subsequence Policy Guidance [2] identify a range of statutory and non-statutory consultees, including the public, where their views should be taken into account in the local authority's LAQM decision-making process.

The Environment Act 1995 provides the minimum legal requirements for consultation and Schedule 11 of the Act states that:

"A local authority in carrying out its functions in relation to a) any air quality review, b) any assessment under section 82 or 84 of this Act, or c) the preparation of an action plan or any revision of an action plan shall consult such other persons as fall within sub-paragraph (2)." Appendix 1 provides a list of statutory consultees as required by the 1995 Act.

The LAQM Policy Guidance [2] recommends wider involvement through the inclusion of other groups, such as residents and local business, in the policy development process. Including non-expert views and opinions reflects a growing trend in environmental decision-making that acknowledges the need for local networks of communities to be involved in the process of LAQM. The guidance also provides suggestions on how local authorities should consult and liaise with others. It is stated clearly that within a full round of air quality review and assessment, there are a number of opportunities for local authorities to consult. Figure 1 illustrates the Government's recommendations on the approach to consultation that should be adopted in the second round of air quality review and assessment. However, the extent of the consultation is at local authorities' discretion. Although there is no need for a full public consultation at each step of the review and assessment process, local authorities will still wish to make their air quality assessments available to the public [2].

\subsection{Local Air Quality Management Consultation}

Previous research on communication initiatives relating to air quality indicates that participants struggled with the scientific concepts and modelling procedures presented. However, given effective access to information, communities are capable of incorporating and integrating a broad range of technical and social factors involved in making viable decisions about local air quality [3]. These findings are in line with earlier study suggesting that the public make sense of air pollution information in relation to their personal experience, put into 'realworld' context [4]. Previous research by Beattie et al [5] suggests that a different range of consultation strategies: one-way (e.g. provision of leaflets in libraries), two-way (e.g. questionnaire survey), and to a limited extent, participative (e.g. 
public meetings and citizen's juries) were used to inform and consult stakeholders about the process of LAQM. General advice on consultation for LAQM is provided by the National Society for Clean Air and Environmental Protection (NSCA) [6]. Details about the process of LAQM are provided by Longhurst et al [7].

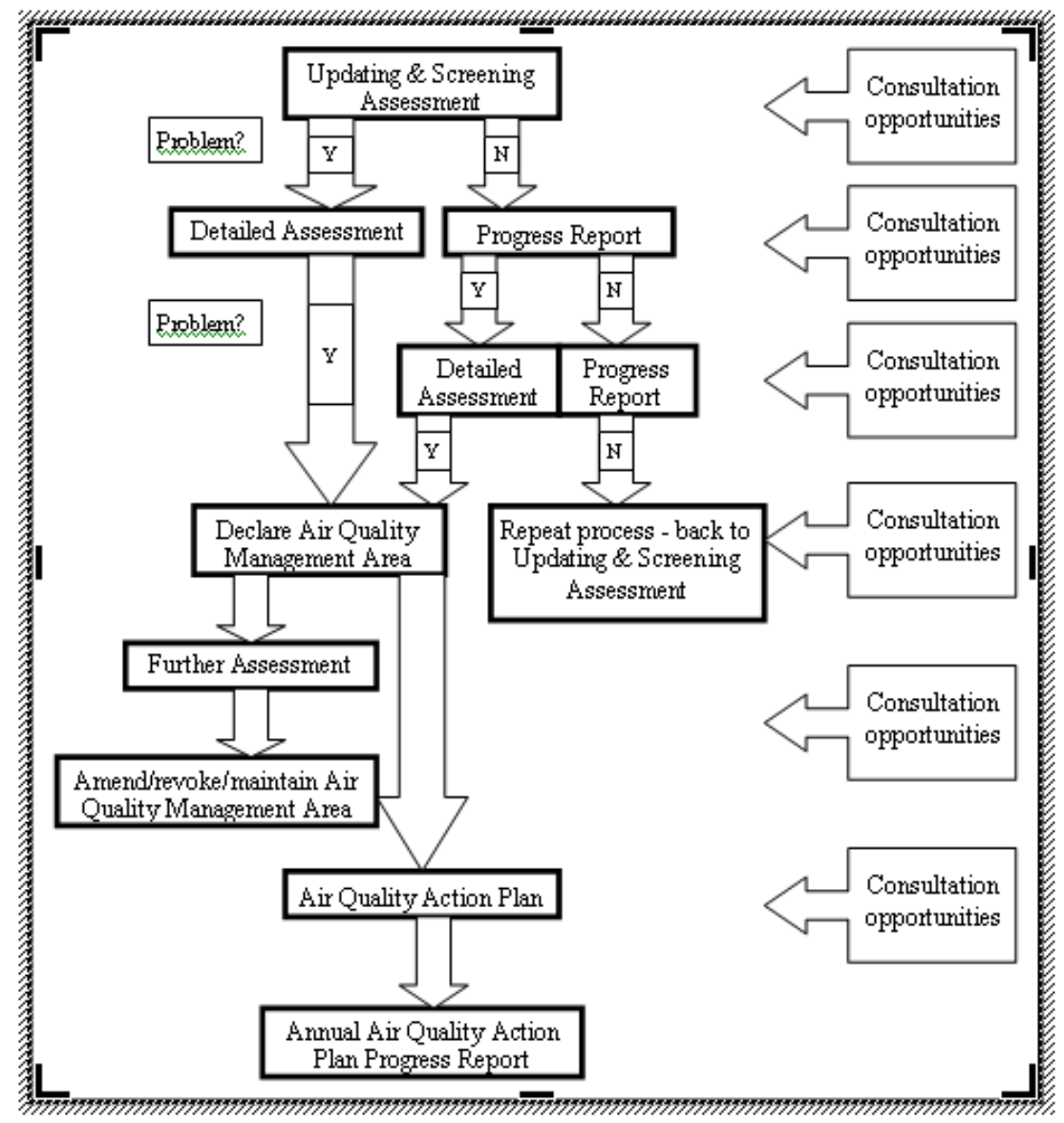

Figure 1: Local air quality management - opportunities for consultation.

This paper will present the outcomes of a 2 year Economic and Social Research Council funded programme addressing how local authorities in England have discharged their air quality duties and responsibilities. The aims of this research were to investigate the nature, scope and effectiveness of local authority's approaches in LAQM consultation and to develop a conceptual model of better practice in LAQM consultation. The latter is discussed elsewhere [8]. This paper will conclude with guidance on steps to better practice to LAQM 
consultation, which is designed for local authorities to engage with stakeholders and local communities in meaningful and effective dialogue on air quality issues.

\section{Methods}

The data presented here are drawn from questionnaire survey and case study research. A semi-structured questionnaire was designed to identify the actual stakeholders consulted by local authorities on air quality related issues, the aspects of review and assessment consulted upon including how stakeholders' views affected decision-making process, and different methods of consultation used. A pilot survey was sent out to all local authorities in Scotland and Northern Ireland. Following minor amendments, a final questionnaire survey was sent by mail to all local authorities in England $(n=353)$, primarily directed at environmental health professionals responsible for implementing the LAQM regime.

Following a rigorous case study selection criteria [9] 11 local authorities were chosen for case study research. Case study authorities were selected to provide a geographical spread throughout England, to represent differing administrative type (a district, London, Metropolitan or unitary authority), and differing local air quality challenges (with or without Air Quality Management Area). Semistructured interviews were used as the primary data source, supplemented with the government archive on air quality, local authority reports and other documentation related to air quality work in the case study locality, as well as their response to the postal questionnaire.

\section{Research findings}

The questionnaire survey provided a broad picture of LAQM consultation practice in English local authorities whilst case studies covered a more limited number of authorities in more depth. These data sources were used to investigate the nature, scope and effectiveness of local air quality management consultation approaches. Responses to the postal questionnaire were received from 150 authorities (a response rate of $42 \%$ ).

Schedule 11 of the 1995 Act requires local authorities to carry out consultation with statutory consultees (see Appendix 1) and subsequent policy guidance advises consultation with the public, local businesses and other stakeholders as appropriate. Given this framework, nearly all survey participants (94\%) stated that they had undertaken consultation although surprisingly the remainder never undertook any consultation on the LAQM process.

\subsection{Local Air Quality Management Consultation practice: stakeholders and their impacts in the decision-making process}

Survey participants were asked to identify internal departments within their local authority and external bodies consulted during the LAQM process. LAQM consultation was carried out primarily by the environmental health department, 
either alone (57\%) or in partnership with other departments $(43 \%)$. A vast majority of internal consultation undertaken to incorporate other departments' views and opinions on air quality management issues was with land-use planners (90\%), followed by consultation with transport planners (77\%) and Elected Members (74\%). Department for Environment, Food and Rural Affairs (Defra) was viewed as the most significant statutory stakeholder although $10 \%$ of participants considered their submission of air quality review and assessment reports to Defra as routine reporting in order to get a seal of approval rather than as consultation. Further results from the survey revealed that residents were considered to be as important as the County Council in LAQM consultation (score 2.1 ; with $1=$ very important to $5=$ not important) whilst neighbouring authorities (score 2.2) were slightly more important than the Environment Agency and Highways Agency (both score 2.3).

Subsequent case studies showed that although most authorities attempted to consult both statutory and non-statutory stakeholders on LAQM issues, there existed a distinct emphasis towards engagement with formal, institutional, and expert statutory consultees. Evidence from case studies suggested a number of reasons for this: a) local authorities tended to "feel at ease with fellow professionals", b) were concerned that "people do not seem to get [understand] the numbers from monitoring and modelling", and c) struggled to elicit responses from non-statutory consultees as "they do not show any real interest". In other words, even though residents were considered as an important stakeholder in the LAQM consultation process, local authorities may have tended to limit their engagement with non-experts, and sought to expand dialogue with a range of expert statutory institutions who were perceived to have a better understanding of, and interest in the underlying science and policy issues.

In order to undertake meaningful consultation, it is important to ensure that all consultees views are considered and incorporated into the decision-making process. In the survey, a question was asked to find out whether consultation actually influences local authority's decision, and if it does, at which stage of the LAQM process. Table 1 shows the extent to which stakeholder views have an impact on different stages of LAQM. The most significant impact was on choosing measures to be put forward in Air Quality Action Plans.

This opinion is confirmed by case study authorities although they also experienced difficulties in integrating the views of non-statutory consultees, which include the public, in the decision-making process, in particular how to weigh, report, and embed responses in Air Quality Action Plans. This is probably because local authorities tended to feel more at ease with statutory consultees, and feel more able to include their responses. Case study research also found that local authorities experienced difficulties in drawing down sufficient funding to implement Action Plans fully. As Action Plans are one area where non-statutory stakeholders were most likely to be involved, there is a view that consultation unfairly raises community's expectations. 
Table 1: Local authority views on the impact of stakeholders' views on LAQM decision-making.

\begin{tabular}{|l|c|}
\hline Decision-making process & Score \\
\hline Decisions to proceed to Detailed Assessment & 3.7 \\
\hline Conclusions of Updating \& Screening Assessment & 3.6 \\
\hline Conclusions of Detailed Assessment & 3.6 \\
\hline Revocation or amendment of Air Quality Management Area & 3.4 \\
\hline Decision to declare Air Quality Management Area & 3.1 \\
\hline Air Quality Management Area boundaries & 3.1 \\
\hline Local Air Quality Strategies & 3.0 \\
\hline Measures put forward in Air Quality Action Plans & 2.5 \\
\hline
\end{tabular}

$* 1=$ very significant and $5=$ insignificant

\subsection{Successful Local Air Quality Management consultation}

While UK policy emphasises the importance of local authority involvement and engagement with a broad range of statutory and non-statutory community stakeholders, the reality of such engagement is often more complex and uncertain.

Local authorities were asked to judge whether LAQM consultation has been undertaken successfully. Only $40 \%$ of survey participants considered their consultation to be successful whilst nearly $44 \%$ were unsure of the outcomes. Reasons why consultation might not be considered successful included: limited responses from consultees, particularly in relation to consultation with the public, lack of interest from and interactions with other departments in the local authority and relevant government bodies, lack of resources and limited experience in consultation. In local authorities' views, the process of consultation can be improved by having more resources i.e. time and funding, sharing best practice, having more training, and making better use of websites. A lack of expertise on undertaking LAQM consultation was also identified. Most questionnaire participants stated that they had never received any formal training. This finding corresponds with case study evidence where local authorities stated lack of experience and expertise in consultation. This is perhaps unsurprising given the range of roles and duties that environmental health departments are expected to perform. In the context of this gap of expertise, the research team have developed a practical guidance document entitled "Steps to Better Practice: Guidance for local authorities on LAQM consultation" [10] (available to download at www.uwe.ac.uk/aqm/esrc).

One case study authority considered to execute "better LAQM consultation practice" [8] demonstrates that effective LAQM consultation can be done. The authority managed to join together statutory and non-stakeholders in carrying out LAQM consultation. These range of stakeholders included officers from environmental health, transport, and planning departments in the local authority, local residents and businesses. More importantly, they were able to maintain active engagement initiatives throughout the years using a pollution 
measurement partnership programme. Consultation works well when nonstatutory stakeholders (informal networks) are empowered to interact with statutory stakeholders (formal networks). This interaction is best enabled by local community champions, advocates of local authorities and politicians. The consultation process also needs to be adequately resourced and carried out over a reasonably extended time-frame. It is also critical to decide the point at which consultation takes place.

\section{Conclusions}

Evidence from questionnaire and case studies suggest that there is no simple solution to successful LAQM consultation. Although local authorities genuinely attempt to engage with all stakeholders, current consultation practices are not working as well as they could. This may imply a re-think on the form and function of LAQM consultation processes. This paper argues that consultation is a key element in LAQM process and meaningful consultation can win public and political supports on what might be difficult and challenging actions to improve air quality. The strategic co-ordination of a range of engagement initiatives contributed to a more effective LAQM consultation process. Early and up-stream engagement practices within the consultation process build local community participation and allow for a clearer broad-based stakeholder constituency to thrive and influence the process of LAQM.

Based on the research findings, a set of parameters have been set to define an integrated LAQM consultation process. The parameters are as follows:

- $\quad$ stakeholder engagement should be early and upstream, and have the capacity to effect real change via a clear association with the LAQM decision-making process;

- stakeholders should be well-informed, be aware of the opportunities to participate and, optimally, be able to engage over an extended time period;

- local authorities and their stakeholders commitment to be involved in the process are best enabled via experienced and effective LAQM advocates of local champions (within the community, local authority, and amongst local politicians);

- consultation works well when local authorities and their communities are able to access adequate resources levered by relevant funding streams;

- trust and capacity building in the process can be built through co-work exercises, for example via pollution measurement partnerships, public health initiatives or relevant environmental and transport projects.

\section{Appendix}

(2) Those persons are -

(a) the Secretary of State;

(b) the appropriate new Agency; 
(c) in England and Wales, the highway authority for any highway in the area to which the review or, as the case may be, the action plan or revision relates;

(d) every local authority whose area is contiguous to the authority's area;

(e) any county council in England whose area consists of or includes the whole or any part of the authority's area;

(f) any National Park authority for a National Park whose area consists of or includes the whole or any part of the authority's area;

(g) such public authorities exercising functions in, or in the vicinity of, the authority's area as the authority may consider appropriate;

(h) such bodies appearing to the authority to be representative of persons with business interests in the area to which the review or action plan in question relates as the authority may consider appropriate;

(i) such other bodies or persons as the authority considers appropriate.

\section{References}

[1] HM Government, Environment Act 1995. Chapter 25, The Stationery Office: London, 1995.

[2] Defra and National Assembly for Wales, Part IV of the Environment Act 1995 Local Air Quality Management. Policy Guidance LAQM. PG(03), Defra: London, 2003.

[3] McDonald, J.S., Hession, M., Rickard, A., Nieuwenhuijsen, M.J., and Kendall, M., Air quality management in UK local authorities: public understanding and participation. Journal of Environmental Planning and Management 45(4), pp. 571-590, 2002

[4] Bickerstaff, K. and Walker, G., Clearing the smog? Public responses to air quality information. Local Environment 11(3), pp. 279-294, 1999.

[5] Beattie, C.I., Longhurst, J.W.S., Woodfield, N.K., Air quality management: evolution of policy and practice in the UK as exemplified by the experience of English local government. Atmospheric Environment 35, pp. 1479-1490, 2001.

[6] NSCA, Consultation for Local Air Quality Management: the how to guide, NSCA: Brighton, 1999.

[7] Longhurst, J.W.S., Beattie, C.I., Chatterton, T.J., Hayes, E.T., Leksmono, N.S., and Woodfield, N.K., Local air quality management as a risk management process: assessing, managing and remediating the risk of exceeding an air quality objective in Great Britain. Environment International 32, pp. 934-947, 2006.

[8] Dorfman, P., Beattie, C.I., Burnet, F., Gibbs, D.C., Leksmono, N.S., Longhurst, J.W.S., Weitkamp, E.L.C., A conceptual model of the role of complex science in local authority consultations about air quality management. Local Environment 11(4), pp. 399-419, 2006.

[9] Dorfman, P., Leksmono, N.S., Burnet, F., Gibbs, D.C., Longhurst, J.W.S., Weitkamp, E.L.C., A preliminary review of local air quality management 
consultation practices in England. Air Pollution XIV, ed. Longhurst, J.W.S. \& Brebbia C.A., WIT Press: Southampton, pp. 145-154, 2006.

[10] Dorfman, P., Leksmono, N.S., Longhurst, J.W.S., Burnet, F., Gibbs, D.C., Weitkamp, E.L.C., Steps to Better Practice: Guidance for local authorities on local air quality management consultation, University of the West of England: Bristol, 2006. Available at www.uwe.ac.uk/aqm/esrc. 